\title{
Effects of Vegetable Oil Reused for Frying on the Liver of Albino Rats
}

\author{
Maduelosi Ngozi Jane ${ }^{1}$, Obediah Gogo Appolos ${ }^{2}$, Ogbonna Ogechi Debora ${ }^{1}$ \\ ${ }^{1}$ Department of Chemistry, Rivers State University, Port Harcourt, Nigeria \\ ${ }^{2}$ Department of Biochemistry, Rivers State University, Port Harcourt, Nigeria
}

Email address:

janemaduelosi@yahoo.com (M. N. Jane)

\section{To cite this article:}

Maduelosi Ngozi Jane, Obediah Gogo Appolos, Ogbonna Ogechi Debora. Effects of Vegetable Oil Reused for Frying on the Liver of Albino Rats. Science Journal of Chemistry. Vol. 7, No. 1, 2019, pp. 11-14. doi: 10.11648/j.sjc.20190701.12

Received: November 9, 2018; Accepted: December 17, 2018; Published: January 30, 2019

\begin{abstract}
The reuse of vegetable oils for food preparation has become a very common practice in both food outlets and homes. Several changes in flavor and taste are observed in the food prepared with reused vegetable oils. This research investigated the effects of vegetable oil used for frying akara balls on lipid profile and liver enzymes of albino rats. Twentyone adult male albino rats (8-12 weeks old) were used for this research. The rats were divided into seven (7) groups, (3 rats per group). They were allowed to acclimatize for a period of one week. Group 1 served as the control group and was fed with feed mixed with unheated vegetable oil. Groups 2-7 were fed with feed mixed with $2 \mathrm{mls}$ of the oil used for frying for a period of two weeks. After the treatment period, they were sacrificed and their blood collected for laboratory analysis. Lipid profile and liver enzymes tests were performed on the collected samples. The results revealed high level of CHOL and LDL, and low levels of HDL, TRIG and VLDL in all the test groups over the control. The levels increased/decreased with frying time. The liver enzymes (ALT, ALP and AST) levels in the test groups were found to be high when compared to the control group. The increased level of enzymes, suggests hepatic injury in the animals fed with reused oil. This suggests that consumption of vegetable oil that has been repeatedly used for frying has harmful effect in the body.
\end{abstract}

Keywords: Albino Rats, Liver Enzymes, Vegetable Oil, Lipid Profile, akara

\section{Introduction}

Edible oils are sources of high energy supply to the body. Each gram of oil or fat supplies $9 \mathrm{kcal}$ of energy which is double the quantity of energy provided by protein and carbohydrate [14]. According to Nutritional Science News of November (1996), the consumption of diet rich in fish oil do not only lower blood cholesterol, triglycerides and lowdensity lipoprotein (LDL, which is the bad cholesterol), but also raises levels of beneficial high-density lipoprotein (HDL, which is the good cholesterol) [2].

Lipids are said to be the second major sources of energy second to carbohydrate. They are required for the absorption and transportation of lipid-soluble vitamins through the blood stream. They are important constituents of many foods and cell membrane. As a result of this, lipids play specific roles in membrane signaling. Thus, in cell development certain lipids are indicators of cellular events and lipids concentration can represent physiological condition of cells
[18].

According to an earlier research carried out, the average number of times a batch of vegetable cooking oils is used before being discarded ranged from three to six times [11]. This is because of its high thermal stability. During the frying process various chemical reactions occur such as thermal oxidation, hydrolysis and polymerization due to the exposure of the oil to high temperature in the presence of air and moisture $[5,12]$.

The repeated heating of oil at high temperature $\left(180^{\circ} \mathrm{C}\right.$ and above) also results in thermal oxidation of the oil which causes the configuration of the fatty acids to change from the cis isomer to the trans isomer [7]. This configuration change causes the polyunsaturated fatty acid to acquire undesirable properties associated with saturated fatty acids such as the correlation with increased serum cholesterol levels and higher lower density lipoprotein (LDL) cholesterol in particular [18].

Oxidation of oil results in formation of various products, 
some of which are toxic. For example, radical species that are generated in the course of oxidation process damage some biomolecules (membrane lipid, protein and DNA) which manifest as cell dysfunction, ageing, cardiovascular and neurodegenerative disease [1]. Also, during oxidation of vegetable oils, the double bonds in the fatty acids are broken, leading to loss of unsaturation in the oil as reported earlier [9].

Liver is an organ in the abdominal cavity of vertebrates that plays a major role in metabolism and has numerous functions in the body including the storage of glycogen, synthesis of plasma protein and detoxification of drugs. It regulates a variety of high volume biochemical reaction requiring specialized tissues [18]. Continuous consumption of oxidized oils contributes to liver, heart and kidney dysfunction. This occurs when the enzymes alanine transaminase, aspartate transaminase, lactate dehydrogenase etc are destroyed or denatured [4]. The sole aim this research is to investigate the effects of vegetable oil repeatedly used for frying akara balls on lipid profile and liver enzymes of albino rats.

\section{Methods}

\subsection{Materials}

\subsubsection{Test Substance}

10 liters of kings vegetable oil was purchased from Mile 3 Market in Port Harcourt, Rivers State, Nigeria, and was used to fry akara balls for 4hours, 8hours, 12hours, 16hours, 20hours and 24hours. After each frying batch, samples of the oil were taken, allowed to cool and stored in an amber sample bottle before being fed to the rats. There was no topping up of oil after each frying batch.

\subsubsection{Laboratory Animals}

Twenty-one adult male albino rats (8-12 weeks old) were used for this research. They were housed, fed and cared for, following International Standard.

\subsection{Experimental}

\subsubsection{Treatment of Animals}

The rats were divided into seven (7) groups with three (3) rats per group. They were allowed to acclimatize for a period of one week. Group 1 served as the control with rats fed with feed mixed with $2 \mathrm{mls}$ of oil that was not used for frying. Group 2 were fed with feed mixed with $2 \mathrm{mls}$ of the oil that was used for frying for a period of 4hours. Group 3 were given feed mixed with $2 \mathrm{mls}$ of oil that was used for frying for 8 hours. Group 4 were given feed mixed with $2 \mathrm{mls}$ of vegetable oil that was used for frying for 12 hours. Group 5 were given $2 \mathrm{mls}$ of vegetable oil that was used for frying for 16 hours. Group 6 were given feed mixed with $2 \mathrm{mls}$ of vegetable oil that was used for frying for 20 hours. Group 7 were given feed mixed with $2 \mathrm{mls}$ of oil that was used for frying for 24 hours. Therefore, the frying was done for four hours daily for a total of two weeks. The animals were also fed for two weeks.

\subsubsection{Blood Collection, Processing and Storage}

After two weeks, the animals were sacrificed and the blood sample of approximately $5 \mathrm{mls}$ was obtained from each research animal and was passed into lithium heparin sample bottles. These bottles were transferred into a container containing ice and were covered immediately to avoid ambient light and heat from impacting on it at the point of collection. The plasma was obtained after centrifugation. This was achieved using RP-1000 centrifuge at 10,000 rpm for a period of 30 minutes. These plasma were individually stored in firmly capped vials at $-4^{\circ} \mathrm{C}$ until ready for use.

\subsubsection{Laboratory Analysis}

Lipid profile and liver enzymes analysis were conducted following methods described by earlier researchers $[6,13]$.

\section{Results}

Table 1. Results of the Lipid profile Tests of the various groups.

\begin{tabular}{|c|c|c|c|c|c|c|c|c|}
\hline & HDL (mmol/l) & TRIG (mmol/l) & CHOL (mmol/l) & LDL (mmol/l) & VLDL (mmol/l) & $\operatorname{ALT}(\mu / \mathbf{l})$ & $\operatorname{ALP}(\mu / \mathbf{l})$ & $\operatorname{AST}(\mu / \mathbf{l})$ \\
\hline GROUP 1 & $1.72 \pm 0.02$ & $3.36 \pm 0.11$ & $3.14 \pm 0.17$ & $0.12 \pm 0.03$ & $1.53 \pm 0.05$ & $40.33 \pm 2.31$ & $55.53 \pm 1.53$ & $30.00 \pm 1.00$ \\
\hline GROUP 2 & $1.60 \pm 0.01$ & $3.03 \pm 0.11$ & $3.66 \pm 0.13$ & $0.68 \pm 0.01$ & $1.38 \pm 0.05$ & $50.33 \pm 2.08$ & $80.73 \pm 1.89$ & $67.00 \pm 9.07$ \\
\hline GROUP 3 & $1.53 \pm 0.03$ & $2.63 \pm 0.06$ & $4.20 \pm 0.38$ & $1.48 \pm 0.04$ & $1.19 \pm 0.03$ & $50.00 \pm 2.00$ & $81.40 \pm 2.60$ & $86.00 \pm 5.20$ \\
\hline GROUP 4 & $1.44 \pm 0.02$ & $2.30 \pm 0.01$ & $4.64 \pm 0.20$ & $2.15 \pm 0.10$ & $1.05 \pm 0.002$ & $55.67 \pm 7.10$ & $85.30 \pm 6.27$ & $85.67 \pm 4.16$ \\
\hline GROUP 5 & $1.34 \pm 0.04$ & $1.90 \pm 0.13$ & $5.45 \pm 0.05$ & $3.24 \pm 0.10$ & $0.87 \pm 0.06$ & $57.33 \pm 9.50$ & $81.80 \pm 1.28$ & $56.33 \pm 10.07$ \\
\hline GROUP 6 & $1.21 \pm 0.01$ & $1.56 \pm 0.06$ & $6.17 \pm 0.09$ & $4.25 \pm 0.10$ & $0.71 \pm 0.03$ & $55.00 \pm 7.00$ & $91.53 \pm 9.70$ & $71.33 \pm 4.51$ \\
\hline GROUP 7 & $1.11 \pm 0.03$ & $1.30 \pm 0.05$ & $6.35 \pm 0.04$ & $4.64 \pm 0.11$ & $0.59 \pm 0.02$ & $46.00 \pm 2.65$ & $84.33 \pm 7.39$ & $66.33 \pm 1.15$ \\
\hline
\end{tabular}

Results expressed as Mean \pm SD

\section{Discussions}

HDL: From the results of analysis done, the HDL level followed a steady decrease with increase in the number of the hours the vegetable oil was used for frying. This implies that fried vegetable oil should not be used/reused for frying for a long period of time as it reduces the HDL level of the consumer of such oil. It is known that high-density lipoprotein (HDL) helps to carry bad cholesterol out of the blood stream and arteries. It also plays a very important role in preventing clogged arteries, so, the higher the HDL number, the better. 
Triglyceride: The triglyceride level was on a steady decrease too when compared with the control that was given unfried vegetable oil. Triglycerides, which are types of blood fats has been linked to heart disease and diabetes [16]. The reduction in triglyceride level may be due to the generation of lipid peroxidation products formed as a result of exposure of the oil to heat for a long period. Hydroperoxides are the primary products of oxidation of oil and their consumption is harmful to the body as reported earlier [8]. This formation of peroxides is an indication of loss of unsaturation in the oil which is not a good result on edible oils.

Cholesterol: The cholesterol level increased appreciatively with increase in the hours of heating. Total cholesterol is an estimate of all the cholesterol in the blood (for example, good HDL plus bad LDL). Thus, higher total cholesterol may be due to high levels of HDL, which is good, or high levels of LDL, which is bad. In this case, the high level of cholesterol in the treated rats is attributed to high levels of LDL which is bad. When compared with the control group, there was regular increase in the cholesterol level as the hours of frying increased. According to medical doctors, a high level of cholesterol may double the risk of heart disease [17].

LDL: From the results obtained, the low density lipoprotein (LDL) level increased with increase in the hours of heating of the oil. High level of LDL results from consumption of vegetable oil used for frying. The LDL level was observed to increase over control. This means that consumption of fried vegetable oil tends to increase the level of LDL level of consumers and this is unhealthy. Lowdensity lipoprotein (LDL) is bad cholesterol and a major contributor to clogged arteries, which levels increase the risk of heart disease [17]. It has been reported that consumption of repeatedly heated cooking oil is associated with increased total serum lipid and low density lipoprotein levels [3]. Also, increase in cholesterol and LDL levels may cause profound alteration in membrane composition, fluidity and function [15].

VLDL: The VLDL levels in the treated rats were observed to decrease over control. This again agrees with result of triglycerides levels obtained since VLDL level is a fraction of triglycerides level.

ALT: From the results of the liver enzymes tests done, the ALT levels of the test groups were found to be higher than the control group. This means that fried oil tends to raise the ALT level. The increase in ALT level is a sign of liver damage as earlier reported [10].

ALP: The ALP levels increased significantly in the rats fed with reused oil. Ideally, ALP level in the blood is low but liver damage puts more ALP into the blood thereby raising its levels. This implies that the high level of ALP found in the test groups when compared to the control is as a result of liver damage.

AST: The AST levels of the test groups were higher than the control. The increased level of enzymes, suggests hepatic injury in the animals fed with reused oil. This is in agreement with the findings reported earlier [15]. The significant release of these enzymes in the animals fed with oxidized vegetable oil can be interpreted to be a result of liver cell destruction and alteration in the permeability of the membrane.

\section{Conclusion}

Consumption of repeatedly used vegetable oil has harmful effects in the body as it increases the levels of enzymes (AST, ALT and ALP) in the blood which is indicative of liver damage. The longer the exposure to heat, the more rancid the oil becomes, hence, the more the damage to the organs. Prolonged exposure to high temperature/repetitive use of vegetable oil for frying food items should be discouraged.

\section{References}

[1] Ayodeji, O. F, Ganiju, O, Adebayo, O. A, Oluwatoyin, V. O. (2015). Consumption of thermally oxidized palm oil diets alters biochemical indices in rats. Beni-Surf University Journal of Basic And Applied Sciences 4 (2), 150-156.

[2] Frank, M. and Painter, D. C. (Nov. 1996). Important fats for the body. Nutritional Science News.

[3] Garrido-Polonio. C, Garcia-Linares, M. C, Garcia-Arias, M. T, Lopez-Varella, S, Garcia-Katragadda, H. R, Fullana, A, Sidhu, $\mathrm{S}$ and Carbonnett-Barrashina, A. A. (2009). Emissions of volatile aldehyde from heated cooking oils. Food Chemistry. 120, 59-65.

[4] Goldberg, J. M. and Kirsch, J. F (1996). Proteins: Structure, Function and Genetics. Medline. 24, 195-208.

[5] Gupta, M. K (2005). Frying Oils. Wiley Online Library 19992017.

[6] Imafidon, K. E. and Okunrobo, L. O. (2012). Study on biochemical indices of liver function tests of albino rats supplemented with three sources of vegetable oils. Nigerian Journal of Basic and Applied Science. 19 (2): 105-110.

[7] Kamsiah, J, Mohd, R. M and Xin-Fang L. (2011). The effects of heated vegetable oils on blood pressure in rats. Clinics, . 66 (12), 2125-2132.

[8] Lapointe, A., Couillard, C., Lemieux, S. (2006). Effects of dietary factors on oxidation of low-density lipoprotein particles. Journal of nutritional biochemistry. 17 (10), 645658 .

[9] Maduelosi, N. J, Obomanu F. G, and Fekarurhobo, G. K. (2012). Dye Sensitized Photo-oxidation of Some Vegetable Oils. Journal of Emerging Trends in Eng. and Appl. Sci.. 3 (5): 740-742.

[10] Maduelosi N. J., and Worlu, G. E (2015). Effect of PhotoOxidized Groundnut oil (Arachis hypogea) on the Liver Enzymes of Albino Rats. International Journal of Advanced Research in Chemical Science.. 2 (11) 5- 7.

[11] Mensah, E and Obeng, G. Y. (2013). Assessment and projection of waste vegetable oil from hotels for biodiesel feedstock and $\mathrm{CO} 2$ savings in Ghana. IntJournal of engineering research and technology. 2, (4), 1-12.

[12] Moreira, R. G, Casteel-Perez, M. E and Barrufet, M. A. (1999). Deep fat frying: fundamentals and applications. Aspen publishers, Galithersburg M. D. 
[13] Onyeike, E. N., Monanu, M. O. and Okoye, C. N. (2012). Changes in the blood lipid profile of wistaralbinorats fed rich cholesterol diet. Annals of Biological Research, 3 (11):51865191.

[14] Saha, S. K, Ahmad, N, Majunder, S, Hosain, M. Z. and Miah, M. A. (2005). Effects of different edible oil on growth performance, different organ weight and serum transaminase in rats. BaglJournal of Vet. Med, 3 (1), 79-81.
[15] Shastry, C. S, Patel, N. Ambala, J. Hand and Aswathranrayana B. J (2011). Evaluation of effect of reused edible oil on vital organs of Wistar rats. Journal of Health Science 1 (4) 10-15.

[16] WebMD (2017), Higher Triglycerides, Topic Overview.

[17] WebMD (2017), Cholesterol management.

[18] Wolfrum, C, and Spenner, F. (2014). Impact of dietary oils and fats on lipid peroxidation in liver and blood of albino rats. Asia Pacific Journal of Tropical Biomedicine 4 (1), 52-58. 